\title{
Appraisal of A1c\% level in healthy Sudanese pregnant women in reference to body mass index
}

\author{
Abdelgadir Ali Elmugadam1, Marwan Ismail ${ }^{2 *}$, Abdelgadir Eltom²
}

${ }^{1}$ Medical Laboratories Sciences, Sudan University of Sciences and Technology, Sudan

${ }^{2}$ Medical Laboratories Sciences, College of Health Sciences, Gulf Medical University, Ajman, UAE

Received: 11 March 2019

Accepted: 09 April 2019

\section{*Correspondence:}

Dr. Marwan Ismail,

E-mail: gadoora428@gmail.com,waw11mar@yahoo.com

Copyright: $\odot$ the author(s), publisher and licensee Medip Academy. This is an open-access article distributed under the terms of the Creative Commons Attribution Non-Commercial License, which permits unrestricted non-commercial use, distribution, and reproduction in any medium, provided the original work is properly cited.

\section{ABSTRACT}

Background: Pregnancy is a major endocrine event in the female lifespan, involving wide-ranged and often dramatic changes in the metabolism of various hormones. Cross sectional, case control, analytical quantitative study was conducted in Sudan, Khartoum state in Yastabsheron obstetric hospital during the period from March to August 2011. Analytical and statistical methods were applied to measure the concentration of A1c\% in healthy pregnant women as well as in healthy non-pregnant women to assess the difference in the results.

Methods: Blood samples were taken from a total of 90 healthy pregnant women (case group) and 30 healthy nonpregnant women (control group), then samples were analyzed for A1c\% by using affinity chromatography technique, and results were recorded in addition to their age, body mass index and the number of pregnancies.

Results: showed that, the mean concentration of the A1c\% in cases group was $(4.407 \pm 1.054 \%)$ in first trimester, $(4.797 \pm 0.631) \%$ in second trimester and $(4.833 \pm 0.626) \%$ in third trimester, and $(5.670 \pm 0.471 \%)$ in control group with a $\mathrm{P}$ value of 0.00 , indicating the highly significant difference between the two groups. Others finding showed that the mean concentration of A1c\% of the first trimester is lower than that of the second and third trimesters, also there was no significant difference between the mean concentration of the second and third trimester. A significant weak positive correlation between A1c\% concentration with body mass index and the age of pregnant women.

Conclusions: Healthy normal pregnant women have lower A1c\% concentrations than non-pregnant women which can be impute to the reduce in plasma glucose values and to the shortened erythrocyte life span that can occur during pregnancy. The body mass index and age affect the concentration of A1c\% c, but it is not affected by gravida.

\section{INTRODUCTION}

Pregnancy is a major endocrine event in the female lifespan, involving wide-ranged and often dramatic changes in the metabolism of various hormones. ${ }^{1}$ It is a normal physiological phenomenon with many biochemical changes that assist the nurturing and with many survival of the fetus.

As gestation progresses, reference ranges for the concentration of many biochemical parameters change significantly from those found in the non-pregnant state.
Gestation-specific reference ranges are essential for correct interpretation of tests used in screening, diagnosis, and monitoring during pregnancy. ${ }^{2}$

Strict glycemic control is essential to minimize the maternal and fetal morbidity and mortality of pregnancies complicated by diabetes. ${ }^{3-5}$

In addition to home blood glucose measurement, which may not always reflect the true average blood glucose level, HbAlc is a useful parameter in metabolic 
regulation. $^{1,6-9}$ Thus, supplementation with HbA1c, as is common outside pregnancy, seems appropriate.

Before pregnancy, the target for metabolic control in women with diabetes is HbA1c values near the normal range. ${ }^{10}$ However, the upper normal range of $\mathrm{HbA} 1 \mathrm{c}$ during normal pregnancy is only sparsely investigated with different methods, mainly in late pregnancy, and reference ranges are generally established from the nonpregnant state. ${ }^{11-13}$

Increased third-trimester $\mathrm{HbAlc}$ levels are associated with an increased risk of preeclampsia, macrosomia and stillbirth leading to speculations that the target for HbA1c in pregnancy should be even lower than outside pregnancy to prevent adverse events. ${ }^{4,5,14}$

Obesity, diabetes and glycaemic control are inter-linked, weight gain is associated with worsening diabetic control and can be exacerbated by therapies aimed at controlling hyperglycemia. Some studies observed that there is a strong relationship between increasing BMI and $\mathrm{HbA} 1 \mathrm{c}$ across all age groups. ${ }^{15}$ There is a need to establish the reference range of $\mathrm{HbA} 1 \mathrm{c}$ during normal Pregnancy with an internationally recognized diabetes Control and Complications Trial (DCCT)-aligned method. In this study, we evaluated the normal upper range of $\mathrm{HbA} 1 \mathrm{c}$ during pregnancy in reference to BMI.

The study objectives included to assess HbA1c in healthy Sudanese pregnant women in reference to BMI, to measure $\mathrm{HbA} 1 \mathrm{c}$ in pregnant women at $1^{\text {st }}, 2^{\text {nd }}$ and $3^{\text {rd }}$ trimester compared to non-pregnant women, to assess the effect of body mass index on HbA1c levels in pregnant women, to correlate $\mathrm{HbAlc}$ to age of pregnant women and the number of pregnancies.

\section{METHODS}

The scope of this quantitative study is to estimate HbA1c in healthy pregnant Sudanese women in reference to BMI. This study is a descriptive cross sectional case control study. This study was carried out in Khartoum state in Yastabsheron obstetric hospital. This study was carried during the period from February to May 2011.

\section{Inclusion criteria}

- The study population comprised of ninety (90) samples collected from apparently healthy pregnant Sudanese women who represent the test group

- Whereas, 30 samples had been collected from apparently healthy non pregnant Sudanese women who represent a control group.

\section{Exclusion criteria}

- Pregnant women with family history of diabetes, history of gestational diabetes, diabetes and anemia
Permission of this study was obtained from the local health authorities in Yastabsheron obstetric hospital. The objectives of the study were explained to all individual participating in this study. An informed consent was obtained and Health education was provided to all participants. Interview with the test group and the control group were done to obtain the clinical data. Clinical assessment was done by a medical doctor. A questionnaire was designed specifically to obtain information's which help in either including or excluding certain individuals in or from the study respectively. In order to measure the body mass index, the following anthropometric parameters were taken into consideration:

\section{Weight and height}

Weight was recorded to the nearest kilograms $(\mathrm{kg})$ with the subject standing on the weighing machine without shoes. The same weighing machine used for all participants and the machine was tested with known set of weights for any error. Height was recorded with the subject erect, bane footed feet together, back and heels against the upright bar of height scale. The height measurement equipment consists of a vertical bar with a steel tape attached perpendicularly to the vertical bar which was brought down snugly on the examinees head. Weight was recorded in $(\mathrm{kg})$ where as height was recorded in $(\mathrm{cm})$.

\section{BMI}

BMI was calculated from the formula:

Weight in kilograms \square of height in meters.

\section{Collection of blood samples}

Venous blood specimens " $3 \mathrm{ml}$ " were collected from participants, using tourniquet, disposable syringe and spirit for sterilization of the area of collection. The collected blood was drawn into EDTA containers, gently mixed. Blood samples were preserved at $2-8^{\circ} \mathrm{C}$ for one week prior to analysis. Obtained blood samples were tested for determination of HbA1c using iron exchange chromatography method. No special patient preparation is required. Fasting specimens are not required. No special additives or preservatives other than anticoagulants are required.

\section{Procedure}

The methodology in the current study included mixing 5 $\mu \mathrm{L}$ of whole blood with R1/Reagent in the test tube, and incubated for 2 minutes. The test tube were remixed and $25 \mu \mathrm{L}$ of the reaction mixture were applied to the test device, then $25 \mu \mathrm{L}$ washing solution added, and the test results read by the Nycocard reader II (www.axisshield.com/NycoCard-HbA1c). Reagents, standard were checked for storage, stability and preparation before starting work. 


\section{Statistical analysis}

Collected data were analyzed by a computer system using statistical package for social science (SPSS) program using the One-Way ANOVA, independent ( $t$ test) and correlation tests.

\section{RESULTS}

During February to May 2011, a total of 90 pregnant women (at the different three trimesters (first, second and third) of pregnancy admitted to Yastabsheron obstetric hospital and a total of 30 females (non- pregnant women) were randomly selected to conduct this study. The two groups were apparently healthy women and they were free of any disorders that can affect the concentration of $\mathrm{HbA}_{1 \mathrm{c}}$. Blood samples were taken from each subject, samples were analyzed for determination of $\mathrm{HbA}_{1 \mathrm{c}}$ concentration and results were recorded in addition to their age, body mass index and the number of pregnancies.

The results obtained were statistically analyzed, using the One-Way ANOVA, independent (t test) and correlation. The level of significance was expressed as $\mathrm{P}<0.05$ for significant, and $\mathrm{P}<0.01$ for highly significant.

Table 1 showed that, the mean concentration of the $\mathrm{HbA}_{1 \mathrm{c}}$ in cases group was $(4.407 \pm 1.044) \%$ in first trimester, $(4.797 \pm .621) \%$ in second trimester and $(4.823 \pm .616) \%$ in third trimester), and $(5.660 \pm .461) \%)$ in control group with a $\mathrm{P}$ value of 0.00 , indicating the highly significant difference between the two groups.

Table 2 showed the significant difference between the mean concentration of $\mathrm{HbA}_{\mathrm{lc}}$ of first $(4.407 \%)$ and second trimesters $(4.797 \%)$.

Table 1: Summarizes comparison of means of HbA1c \% between study and control groups.

\begin{tabular}{|c|c|c|c|c|c|}
\hline \multirow{2}{*}{ Variable } & \multicolumn{3}{|l|}{$\begin{array}{l}\text { Cases group } \\
\mathbf{N}=90\end{array}$} & \multirow{2}{*}{$\begin{array}{l}\text { Control group } \\
\mathbf{N}=\mathbf{3 0}\end{array}$} & \multirow[t]{2}{*}{ P value } \\
\hline & First trimester & Second trimester & Third trimester & & \\
\hline $\mathrm{HbA}_{1 \mathrm{c}} \%$ & $4.407( \pm 1.054) \%$ & $4.797( \pm .631) \%$ & $4.823( \pm .626) \%$ & $5.670( \pm .71) \%$ & 0.00 \\
\hline
\end{tabular}

The mean difference is significant at the 0.05 level; The table shows the mean $+\mathrm{SD}$, range in brackets ( ) and probability $(\mathrm{P})$ value.

Table 2: Summarizes comparison of means of HbA1c \% between first and second trimester.

\begin{tabular}{|l|llll|l|}
\hline Variable & Stage of pregnancy & $\mathbf{N}$ & Mean & Std. Deviation & Sig. \\
\cline { 1 - 5 } $\mathrm{HbA}_{1 \mathrm{c}} \%$ & First trimester & 30 & 4.407 & 1.0448 & .013 \\
\cline { 2 - 5 } & Second trimester & 30 & 4.797 & .6217 & \multirow{2}{*}{} \\
\hline
\end{tabular}

The mean difference is significant at the 0.05 level.

Table 3: Summarizes comparison of means of HbA1c \% between first and third trimester.

\begin{tabular}{|l|llll|l|}
\hline Variable & Stage of pregnancy & $\mathbf{N}$ & Mean & Std. Deviation & Sig. \\
\cline { 1 - 5 } $\mathrm{HbA}_{1 \mathrm{c}} \%$ & First trimester & 30 & 4.407 & 1.0448 & .011 \\
\cline { 2 - 5 } & Third trimester & 30 & 4.823 & .6163 & \multirow{2}{*}{} \\
\hline
\end{tabular}

The mean difference is significant at the 0.05 level.

Table 4: Summarizes comparison of means of HbA1c \% between second and third trimester.

\begin{tabular}{|l|llll|l|}
\hline Variable & Stage of pregnancy & $\mathbf{N}$ & Mean & Std. Deviation & Sig. \\
\hline \multirow{2}{*}{$\mathrm{HbA}_{1 \mathrm{c}} \%$} & Second trimester & 30 & 4.797 & .6217 & 0.955 \\
\cline { 2 - 5 } & third trimester & 30 & 4.823 & .6163 & 0 \\
\hline
\end{tabular}

The mean difference is significant at the 0.05 level.

Table 3 showed the significant difference between the mean concentration of $\mathrm{HbA}_{1 \mathrm{c}}$ of first $(4.407 \%)$ and third trimesters $(4.823 \%)$. Table 4 showed the insignificant difference between the mean concentration of $\mathrm{HbA}_{1 \mathrm{c}}$ of second $(4.797 \%)$ and third trimesters $(4.823 \%)$. Figure 1 showed the correlation between $\mathrm{HbA}_{1 \mathrm{c}}$ and body mass indexes in cases group $(r=0.268)(p$ value $=0.011)$.
Figure 2 showed the correlation between $\mathrm{HbA}_{1 \mathrm{c}}$ and age in cases group $(r=0.232)$ ( $\mathrm{p}$ value $=0.028)$.

Figure 3 showed the correlation between $\mathrm{HbA}_{1 \mathrm{c}}$ and number of pregnancies in cases group $(r=0.130) \quad(p$ value $=0.221$ ). 


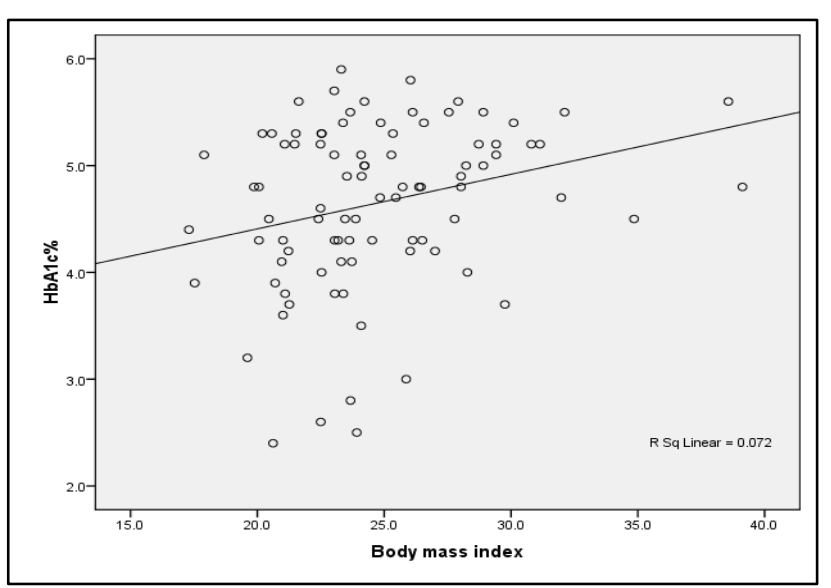

Figure 1: The scatter plot of HbA1c concentrations and body mass index showed the significant weak positive correlation on this figure. $(r: 0.268),(p$ value:0.011).

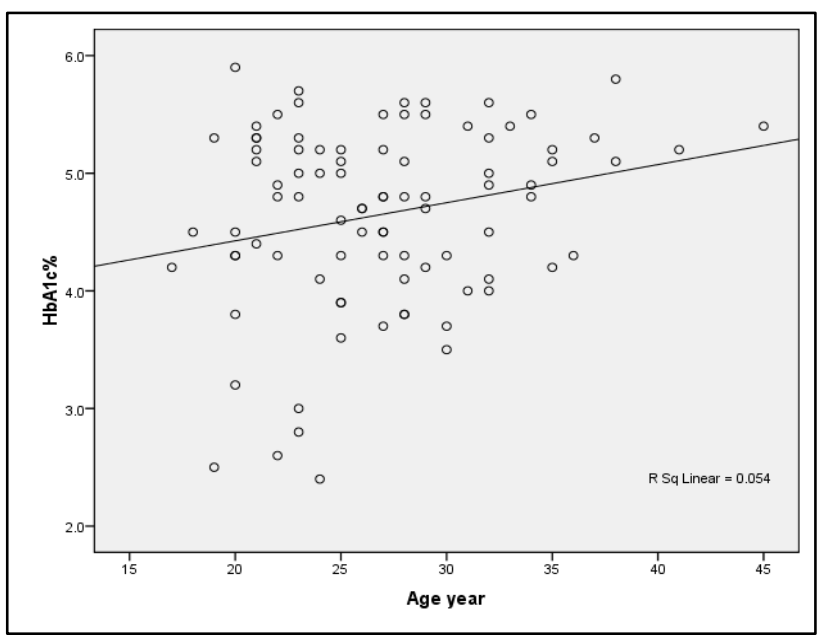

Figure 2: The scatter plot of HbA1c concentrations and age showed the weak positive significant correlation on this figure. $(\mathbf{r}: 0.232)$, ( $p$ value:0.028).

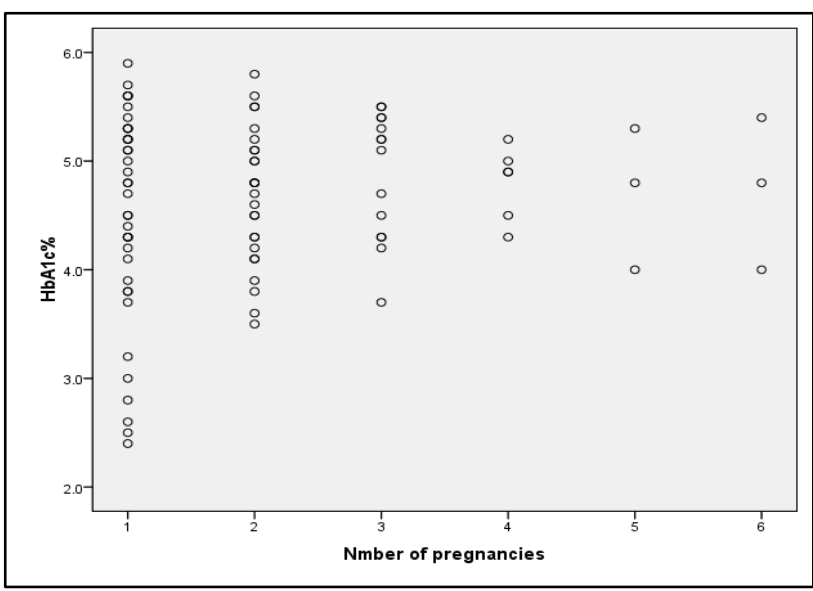

Figure 3: The scatter plot showed the insignificant weak positive correlation between HbA1c concentrations and the number of pregnancies on this figure. (r: 0.130), (p.value:0.221).
There were three babies who developed respiratory complication 24 hours after birth (not related to prematurity) and required respiratory support. All these 3 babies survived and were discharged subsequently. Of the two intrapartum stillbirths noted in the study, one was a severe IUGR at 30 weeks and the other had intrapartum fetal distress at 32 weeks leading to stillbirth. The abnormal waveform indices were compared with major adverse outcomes (Table 1).

\section{DISCUSSION}

The present study was carried out in order to measure the concentration of $\mathrm{HbA1c}$ in pregnant women at the different stages of pregnancy as well as in non-pregnant women to detect if there are any differences between results and to ensure proper interpretation of laboratories result may obtained for the whole study group.

Elevated $\mathrm{HbA} 1 \mathrm{c}$ is associated with increased risk of adverse pregnancy outcomes (e.g., abortion, stillbirth, and congenital abnormalities). ${ }^{16}$ Some previous study found that even a slightly raised $\mathrm{HbA1c}$ level was positively associated with an increased risk of major congenital abnormalities. ${ }^{17}$

The statistical analysis showed that the mean concentration of $\mathrm{HbA} 1 \mathrm{c}$ in pregnant women in the different trimesters of pregnancy was lower than the mean of non-pregnant women.

The study also showed that the mean concentration of $\mathrm{HbA} 1 \mathrm{c}$ of the first trimester is lower than that of the second and third trimesters, but there was no significant difference between the mean concentration of the second and third trimester.

On the other hand, the study showed that there was a significant weak positive correlation between HbA1c concentration with all of body mass index and the age of pregnant women, but an insignificant weak positive correlation with the number of pregnancies.

In comparison to a previous study, there was an agreement between this study and the study was conducted by Andrea Mosco, et al and Abdelgadir A, and for determination of $\mathrm{HbA} 1 \mathrm{c}$ in Healthy pregnant women in which Healthy pregnant women have lower HbAlc concentrations than non-pregnant women, due to the decrease in plasma glucose values and to the shortened erythrocyte life span that occur during pregnancy. ${ }^{18}$ So, the reference intervals for $\mathrm{HbAlc}$ in pregnant women should therefore be lower than those currently in use. ${ }^{19}$ Also, this study agrees with another previous study, which was conducted by $\mathrm{C}$ Jacques, et al, in which they estimate $\mathrm{HbA} 1 \mathrm{c}$ in different stages of healthy pregnant women and found that HbA1c levels progressively decreased during the first 25 weeks of pregnancy, then remained stable. ${ }^{20}$ 
The study also agreed with the study of Nilsen JR, et al which found that $\mathrm{HbA} 1 \mathrm{c}$ was significantly decreased early in pregnancy and further decreased in late pregnancy compared with age-matched non pregnant women. $^{21}$

\section{CONCLUSION}

Healthy pregnant women have lower HbA1c concentrations than non-pregnant women which can be attributed to the decrease in plasma glucose values and to the shortened erythrocyte life span that occur during pregnancy. The body mass index and age affect the concentration of HbAlc, but it is not affected by the number of pregnancies. So, the reference intervals for HbA1c in pregnant women should therefore be lower than those currently in use for non-pregnant women.

\section{REFERENCES}

1. Marshall SM, Barth JH. Standardization of HbA1c measurements: a consensus statement. Diabet Med. 2000;17(1):5-6.

2. HuyA. Biochemical test in pregnancy. Australian Prescriber. 2005;28:96-101.

3. Evers IM, de Valk HW, Mol BW, ter Braak EW, Visser GH: Macrosomia despite good glycaemic control in type I diabetic pregnancy: results of a nationwide study in the Netherlands. Diabetologia. 2002;45(11):1484-9.

4. Lauenborg J, Mathiesen ER, Ovesen P, Westergaard JG, Ekbom P, Molsted-Pedersen L, et al. Audit on stillbirths in women with pregestational type 1 diabetes. Diabetes Care. 2003;26:1385-9.

5. Ekbom P, Damm P, Nogaard K, Clausen P, FeldtRasmussen U, Feldt-Rasmussen B, et al. Urinary albumin excretion and 24-hour blood pressure as predictors of pre-eclampsia in type I diabetes. Diabetol. 2000;43(7):927-31.

6. Kyne-Grzebalski D, Wood L, Marshall SM, Taylor R. Episodic hyperglycaemia in pregnant women with well-controlled type 1 diabetes mellitus: a major potential factor underlying macrosomia. Diabet Med. 1999;16(8):702-6.

7. Hartland AJ, Smith JM, Clark PMS, Webber J, Chowdhury T, Dunne F. Establishing trimester- and ethnic group-related reference ranges for fructosamine and $\mathrm{HbA1c}$ in non-diabetic pregnant women. Ann Clin Biochem. 1999;36(Pt 2):235-7.

8. O'Kane MJ, Lynch PLM, Moles KW, Magee SE. Determination of a diabetes control and complications trial-aligned $\mathrm{HbA} 1 \mathrm{c}$ reference range in pregnancy. Clin Chim Acta. 2001;311(2):157-9.
9. Kilpatrick ES. Glycated haemoglobin in the year 2000. J Clin Pathol. 2000;53:335-9.

10. Kendrick JM. Preconception care of women with diabetes. J Perinat Neonatal Nurs. 2004;18(1):14-25.

11. Worth R, Potter JM, Drury J, Fraser RB, Cullen DR: Glycosylated haemoglobin in normal pregnancy: a longitudinal study with two independent methods. Diabetol. 1985;28(2):76-9.

12. Parentoni LS, de Faria EC, Bartelega MJ, Moda VM, Facin AC, Castilho LN. Glycated hemoglobin reference limits obtained by high performance liquid chromatography in adults and pregnant women. Clin Chim Acta. 1998;274(1):105-9.

13. Lind T, Cheyne GA. Effect of normal pregnancy upon the glycosylated haemoglobins. $\mathrm{Br} \mathrm{J}$ Obstet Gynaecol. 1979;86(3):210-3.

14. Evers IM, de Valk HW, Visser GH. Riskof complications of pregnancy in womenwith type 1 diabetes: nationwide prospectivestudy in the Netherlands. BMJ 2004;328:915-918.

15. Richardson T, Kerr D. Obesity in type 2 diabetes local experience in a district general hospital. $\mathrm{Br} \mathrm{J}$ Diabetes Vasc Dis. 2003;3:49-52.

16. Greene MF. Spontaneous abortions and major malformations in women with diabetes mellitus. Semin Reprod Endocrinol. 1999;17:127-36.

17. Suhonen L, Hiilesmaa V, Teramo K. Glycaemic control during early pregnancy and fetal malformations in women with type I diabetes mellitus. Diabetol. 2000;43:79-82.

18. Abdelgadir AA, Ahmed LO, Ma BA. Correlation of oxidative stress markers malondialdehyde (MDA), antioxidant vitamins $\mathrm{A}, \mathrm{E}$, and $\mathrm{C}$ with glycated hemoglobin (HBA1C) levels in Type 2 diabetes mellitus. Asian J Pharm Clin Res. 2018;5:281-3.

19. Mosca A, Paleari R, Maria G. Dalfrà. Reference Intervals for Hemoglobin A1c in pregnant women: Data from an Italian multicenter study. Am Assoc Clin Chem. 2006;52:1138-43.

20. Jacques C, North ML, Pinget M, Moeglin D, Mayer S, Gandar R. Dorner Hemoglobin A1c and its variations in pregnancy. La Presse Medicale.1983;12(11):673-6.

21. Nilsen JR, Ekbom P, Damm P. HbA1c level are significantly lower in early and late pregnancy. Am Diabet Assoc. 2004;27:1200-1.

Cite this article as: Elmugadam AA, Ismail $M$, Eltom A. Appraisal of A1c\% level in healthy Sudanese pregnant women in reference to body mass index. Int $\mathbf{J}$ Reprod Contracept Obstet Gynecol 2019;8:1835-9. 